\title{
An Assessment of the Practice of Public Relations in Eastern Zone of Tigray
}

\author{
Bereket Yeheysh \\ Department of Journalism, Media and Communications Adigrat University, P.O.Box.50 Adigrat University, Tigray, Ethiopia
}

\begin{abstract}
The research was conducted to assess the practice of Public Relations in Eastern Zone of Tigray, and to do so, the researcher used mixed approach. A questionnaire was used to collect the both quantitative and qualitative data from Public Relation (PR) practitioners, employees, and external publics of the Weredas. The findings of the study depicted that professional Public Relations practice in the eastern zone of Tigray is at infant stage because the PR office is not professionally and structurally organized though its key role is well recognized. The PR practitioners have not well understood the concept of Public relations especially its management function to create mutual understanding with the publics rather they are considered to stage the debate other than mediates it. The PR office uses different tools which are not enough in number and frequency to reach the public on regular basis. Concerning the challenges, lack of skilled human power(professionals), passive attitude towards the office (belittling) especially from the top leaders, absence of adequate capacity building trainings, structure of the office (personnel), lack of logistics (electronic equipments) and financial constraint, absence of professional leadership, lack of infrastructure (to reach village publics), reluctance of sector offices, and inadequate assistance from the region's communication bureau were highly challenging the practice Public Relations in the Weredas of Eastern Zone of Tigray. Based on this, the researcher calls up on the concerned body to organize the practice professionally and structurally, and if a conducive environment prevails and appropriate measures are taken, better prospects lie ahead for the practice of professional public relations.
\end{abstract}

Keywords: Public Relations, Practice, Wereda, Publics

\section{Background of the Study}

Communication is the hub of daily activity of human being, and the history of human communication is mainly associated with the medium that has been used to communicate each other. According to McLuhan (in Griffin 2012), the history of human communication is divided into four levels: a tribal age (hearing, touch, taste, and smell), a literate age (Invention of Phonetic Alphabet), a print age (Invention of Printing Press), and an electronic age (Invention of Telegraph), and he has also questioned the fifth age the digital age (Internet: global village) based on the medium that has been facilitating the communication process. This human communication process has brought communication to the stage of competition on relations among organizations to save their customers within their track.

Among the communication strategies, Public relation has been identified as the effective way of delivering message to the targeted group, and the main objective of public relations is to communicate information that will influence people. M. Zappala and R. Carden (2004). The reason behind this assumption is considering PR as a tool to aware and save the public within the domain for mutual benefit on a mutual agenda. That is why; PR is defined as Deliberate, Planned, Performance based, keep Public Interest, pursuit Two-way Communication and part of Management Function.

With the advancement of technology, organizations have been implementing different communication strategies to reach the targeted public. This emanated from the ancient Romans coined expression "The voice of the people is the voice of the God." Therefore, listening the heartbeat of the concerned public has not been a matter of choice rather taking it as the only way to meet the interest of the public. In this regard, Brian and Deirdre (2009:7) clearly state how
Public Relations can influence individuals while making choices as follows:

PR is evolving quickly, from the technology used, to the changing market dynamics, to the increased demands and empowerment of the twenty-first-century consumer. Most important, the principles and channels you use to reach people, whether influencers or your direct customers, are also changing.

In public relations influencing people is not easy as slaughtering a chicken rather it needs a systematic way and tool as per the nature of the public. For this reason, Print and broadcast media outlets should be prepared, and public discussion forums have to be arranged to bring the hidden to the light. Though public officials have the capacity to lead the people, it is worthless if it is not accompanied with effective public relation activities that can show them the line how to reach and win the mass using different communication tools because it carefully studies the interest of the customers, and consults the management body and designs the best way to prevail good governance, democracy, economic growth etc in the environment. In other words, PR strives to ensure the interest of the people with the help persuasion that is exercised by PR practitioners. In this regard Berhanu (in Nigusse 2008:217) strengthens the aforesaid idea as follows:

The idea that public relations is a process of forging closer understanding between an organization and its publics runs through the teachings of the discipline ,one of the pillars of which is the art and science of Communication.

The history of PR in Ethiopia goes back to the era of queen Sheba, who traveled to Jerusalem to benefit from King Solomon's wisdom, and this is considered as breaking through for the beginning of PR in Ethiopia. Following the establishment of Ethiopian Civil service Agency, it includes

Volume 6 Issue 1, January 2017

www.ijsr.net

Licensed Under Creative Commons Attribution CC BY 


\section{International Journal of Science and Research (IJSR) \\ ISSN (Online): 2319-7064}

Index Copernicus Value (2015): 78.96 | Impact Factor (2015): 6.391

public relation within the structure of government institutions; however, it was not internalized, and remained theoretical because practitioners were not invited to involve in the management decisions that is the core concept of Public Relations. Now days, public relation activities are mainly considered as hub of developmental activities; thus, in each government offices, there is public relation office. Among these offices, Eastern zone weredas are mentioned, and they are involving in the developmental activities of the zone in general and in their surrounding in particular.

\section{Statement of the Problem}

Public relation has a pivotal role in realizing all rounded development of a given society. It is mainly an instrument for leaders in business, government and other institutions to build beneficial relationships with other organizations and groups who have an interest on a given issue. Thus, public relations greatly helps to create a conducive environment which keeps mutual understanding for mutual benefit, and this emanated from the very reason of public relations for development (Vivan, 2003). Good governance, democracy and justice are always with the demanding society, and these values highly take the society one step ahead for a better administration. That is why, the public relation practitioners should be committed to break any silence that might affect their organizations and clients interest. Concerning the practice of public relations, Agee (1985) says "public relation practice-at its best affords genuine opportunities for meaningful service to the society."

Every organization must disseminate information that includes facts and forthcoming events, and details on previous achievements. This information ultimately shapes the public's perception of that organization-in other words, its image. To do so, qualified human power is highly needed because public relation activity is a combination of different disciplines which carefully understand what PR is Harrower (2007).

In Ethiopia, The practice of public relations is found at the infant stage, and this mainly emanated from lack of having skilled manpower in the form of division in relation to the profession. Thus, the activities are limited to routine assignments other than including various parts of the profession like public affairs, employee relations, financial relations and investor relations etc. As a result, the intended objectives of the discipline might be failed to be accomplished Berhanu (cited in Nigusse, 2008).

The public relation offices of eastern zone weredas seem in line with the aforementioned limitations, and may not be playing the role the office is expected of. Therefore, the research attempts to assess the practice of Public relations in eastern zone of Tigray (weredas) to extract challenges and prospects.

\section{Methodology}

\section{Research Design}

The basic research questions in line with the objectives of the research should be studied with an appropriate design that can avoid ambiguity on the research findings. Thus, the researcher employed mixed research approach so that it could extract the findings in line with the objectives of the research.

\section{Data Source and Sampling Technique}

The researcher used primary data sources, and subjects of the study were PR practitioners, employees of selected sector offices and external publics. Purposive sampling was employed for the PR practitioners and sector offices whereas simple random sampling was employed for the employees of sector offices and external publics of the Wereda respectively. Accordingly, from the eight Weredas ten key sector offices were selected and from each office one employee was taken, and five external publics from each Werda were selected randomly using lottery method.

\section{Data Collection and Analysis}

A questionnaire was employed to collect both quantitative and qualitative data from PR practitioners, employees of sector offices and customers of the Wereda. As a result, among the distributed questionnaires 22 out of 24 from the practitioners, and all questionnaires $80 \& 40$ from both the employees of sector offices and customers were collected accordingly.

Following the compilation of the data collection, PR practitioners, employees and customers of the Weredas responses were coded and entered in SPSS version 20 software for statistical analysis, and quantitative data analyses were carried out using simple and relevant statistical methods such as average, percentage and frequency distributions, and the qualitative data were analyzed through organizing the information in line with the quantitative. The analysis of the data was accompanied by thematic coding based on the objectives and questions of the study.

\section{Result and discussion}

\section{Stakeholders' Perception towards Public Relations}

Table 1: Response of the practitioners (attitude) on significance PR office

\begin{tabular}{|c|c|c|c|}
\hline $\mathrm{S} / \mathrm{N}$ & Alternatives & Frequency & Percent \\
\hline 1. & Yes & 21 & 95.5 \\
\hline 2 & No & 1 & 4.5 \\
\hline \multicolumn{2}{|r|}{ Total } & 22 & 100 \\
\hline
\end{tabular}

As the table depicts, 21 (95.5\%) of the practitioners thought that their office has a key role in the activities of the Wereda because the PR office is the one in a position to build a positive image towards the Wereda through expanding its magnificent activities being as a bridge between the Wereda and the people (stakeholders).Therefore, it can be said that the practitioners are confident enough about the inevitability of PR office in the overall footprints of the Wereda. In a nutshell, Public Relations is primarily about image and it plays a role in communicating our image to the various publics to which we relate. 


\section{International Journal of Science and Research (IJSR) ISSN (Online): 2319-7064}

Index Copernicus Value (2015): 78.96 | Impact Factor (2015): 6.391

Table 2: Response employees of sector offices on rating the significance of PR office

\begin{tabular}{|c|c|c|c|}
\hline S/N & Alternatives & Frequency & Percent \\
\hline 1 & Very High & 12 & 15.0 \\
\hline 2 & High & 37 & 46.2 \\
\hline 3 & Medium & 28 & 35.0 \\
\hline 4 & Low & 3 & 3.8 \\
\hline \multicolumn{2}{|c|}{ Total } & 80 & 100.0 \\
\hline
\end{tabular}

Table 2 reveals that from the 80 employees of sector offices respondents, 12(15\%) said 'Very high', 37(46.2\%) 'High', 'Medium' 28(35\%), and 'Low' 3(3.8\%) to the item which let them to reflect about their stance towards the Public Relations office. At this juncture, the conclusion could safely be reached that most of the employees recognized with a significant number in the range of Very High and High the office's role to their offices daily activities.

In addition, when they were questioned their reason for the above mentioned response, most of the respondents stated that they look after the public Relations office for publicity purpose only. This clearly indicates that the sector offices consider the PRo as only a way to media outlets (Media coverage) which neglects the office's unreserved and all rounded contribution as expert Prescriber, ProblemSolving facilitators, and communication facilitator apart from communication technician role.

In line with the finding, Vivan (2003) states that misconceptions about public relations has limited its area and been considered as a one way street for institutions and individuals to communicate to the public; however, public relations own a vast area which improve the functioning of democracy and good governance by encouraging the exchange of information and ideas on public issues.

Table 3: Response of the practitioners on understanding concept of PR

\begin{tabular}{|c|c|c|c|}
\hline S/N & Alternatives & Frequency & Percent \\
\hline 1 & Yes & 17 & 77.3 \\
\hline 2 & No & 5 & 22.7 \\
\hline \multicolumn{2}{|c|}{ Total } & 22 & 100.0 \\
\hline
\end{tabular}

As can be seen from table 3, 17(77.3\%) of the practitioners replied 'Yes' and 5(22.7\%) 'No', and this implies most of the practitioners think that they are well familiar with the concept of Public Relations. When they were asked to define it, they have enumerated the key aspects of PR, but they have never touched the management function of PR which clearly recognizes its part on strategic planning and decision making. Thus, it can be concluded that the PR office is not involving in such activities which are among the key roles and responsibilities of the profession. Cutlip, Center and Broom (2000) define public relations as a management function that establishes and maintains mutually beneficial relationships between an organization and the publics on whom its success or failure depends.
Table 4: Response of external publics on rating PR office's effort to create mutual understanding

\begin{tabular}{|c|c|c|c|}
\hline S/N & Alternatives & Frequency & Percent \\
\hline 1 & Very High & 4 & 10.0 \\
\hline 2 & High & 12 & 30.0 \\
\hline 3 & Medium & 12 & 30.0 \\
\hline 4 & Low & 10 & 25.0 \\
\hline 5 & Very Low & 2 & 5.0 \\
\hline \multicolumn{2}{|c|}{ Total } & 40 & 100.0 \\
\hline
\end{tabular}

Table 4 states that from the 40 external publics $4(10 \%)$ said 'Very high', 12(30) 'High', 'Medium' 12(30\%), 'Low' $10(25 \%)$ and 'Very low' $2(5)$ to the question which let them to rate the effort made by the PR office on creating mutual understanding with the public. This shows us that a significant number portrays passive involvement of the PR office in making the alignment of the organizations selfinterests with the publics concerns and interests which should never be bargained in the arena Public relations, and they stated that too bureaucratic services and negligence of the civil servants during the working hours as manifestations. This is totally against the principles of Public Relations, and Berhanu (in Nigusse 2008:217) strengthens the finding aforesaid idea saying, "The idea that public relations is a process of forging closer understanding between an organization and its publics runs through the teachings of the discipline, one of the pillars of which is the art and science of Communication."

Table 5: Response of the practitioners (attitude) on PR office's professional structure

\begin{tabular}{|c|c|c|c|}
\hline S/N & Alternatives & Frequency & Percent \\
\hline 1 & Yes & 10 & 45.5 \\
\hline 2 & No & 12 & 54.5 \\
\hline \multicolumn{2}{|c|}{ Total } & 22 & 100.0 \\
\hline
\end{tabular}

As the table indicates that out of the 22 practitioners, $10(45 \%)$ said 'Yes', and $12(54 \%)$ 'No' when they treated the question. The reason stated behind most respondents said encompasses both the materialistic and humanistic aspect which shows lack of professionals who are close to the profession, and having scarce resource to prepare PR tools (both print and broadcast). Regarding the professionals, specifically, the head and vice heads are nominated from any profession on political stance basis, and some practitioners are not close friends of Journalism, Literature and other related fields to the practice. In addition, the office is considered as supportive and not given due emphasis by the Wereda. Hence, it is possible to conclude that the office is not structured and organized professionally.

Table 6: Response of the employees (attitude) on PR office's professional structure

\begin{tabular}{|c|c|c|c|}
\hline S/N & Alternatives & Frequency & Percent \\
\hline 1 & Yes & 38 & 47.5 \\
\hline 2 & No & 42 & 52.5 \\
\hline \multicolumn{2}{|c|}{ Total } & 80 & 100.0 \\
\hline
\end{tabular}

From the table it could be said that, the out of the respondents 42(52.5\%) said 'No' and 38(47.5\%) 'No' respectively. Thus, most of the respondents believed that the PR office is not erected professionally, and they justified that the people who assigned to the office are passive and 


\section{International Journal of Science and Research (IJSR) \\ ISSN (Online): 2319-7064}

Index Copernicus Value (2015): 78.96 | Impact Factor (2015): 6.391

transferred from other offices on inefficiency basis, and it served as a "fortification" for the abovementioned reasons.

Based on table 5 and 6 , it can be said that both the PR practitioners and employees have similar stance on the professional practice of the public relations office. In this regard, Harrower (2007) underlines that qualified human power is highly needed because public relation activity is a combination of different disciplines which carefully understand what PR is.

\section{Attempts of the Public Relations office to reach the public}

Table 7: Response of the practitioners on the frequency of reaching the public

\begin{tabular}{|c|c|c|c|}
\hline S/N & Alternatives & Frequency & Percent \\
\hline 1 & Seldom & 12 & 54.5 \\
\hline 2 & Sometimes & 3 & 13.6 \\
\hline 3 & Always & 1 & 4.5 \\
\hline \multirow{2}{*}{4} & Usually & 6 & 27.3 \\
\cline { 2 - 4 } & Total & 22 & 100.0 \\
\hline
\end{tabular}

According to the table, from the total respondents 12 $(54.5 \%)$ said 'Seldom', 'Usually' 6 (27.3\%), 3(13.6\%) 'Sometimes' and 1(4.5\%) Always. Lack of logistics and misunderstanding the mission of the office are the key setbacks on the efforts made to reach the public. As a result, most of the time the practitioners remain stages the debate rather than mediates the debate because they are considered as propagandist. The very unsatisfactory thing depicted in the table is that considerable number of the respondents said seldom. In this regard, the conclusion never escapes from stating that there is a gap that has to be narrowed as to enhance mutual understanding between the public and the Wereda, and the PR has neglected the hub of Public relations because Public relations greatly helps to create a conducive environment which keeps mutual understanding for mutual benefit, and this emanated from the very reason of public relations for development (Vivan, 2003).

Table 8: Response of employees on the frequency of the PR office help their office to reach its public

\begin{tabular}{|c|c|c|c|}
\hline S/N & Alternatives & Frequency & Percent \\
\hline 1 & Seldom & 23 & 28.8 \\
\hline 2 & Sometimes & 25 & 31.2 \\
\hline 3 & Always & 14 & 17.5 \\
\hline 4 & Usually & 8 & 10.0 \\
\hline 5 & Never & 10 & 12.5 \\
\hline \multicolumn{2}{|c|}{ Total } & 80 & 100.0 \\
\hline
\end{tabular}

Table 8 depicts that from the total respondents $23(28.8 \%)$ replied 'Seldom', 25(31.2\%) 'Sometimes',14(17.5\% ) 'Always', 'Usually' 8 (10\%), and 'Never' 10(12.5\%) respectively. In addition, among the respondents who said 'Never' accompanied the reason with their passive attitude which emanates from being careless and assuming the practitioners would not do any different that can significantly take one step ahead the relation they have with their clients. Therefore, it is possible to conclude that the PR office is not helping the sector offices to reach their publics on regular basis which misses among the basic components of Public relations i.e. Community relations. According to the Public Relations Society of America, PR practitioners should have a planned activity with a community to maintain an environment that benefits both the organization and the community, which is not described in the finding of the research.

Table 9: Response of the practitioners on having PR tools

\begin{tabular}{|c|c|c|c|}
\hline $\mathrm{S} / \mathrm{N}$ & Alternatives & Frequency & Percent \\
\hline 1 & Yes & 21 & 95.5 \\
\hline 2 & No & 1 & 4.5 \\
\hline \multicolumn{2}{|r|}{ Total } & 22 & 100.0 \\
\hline
\end{tabular}

From the above table, it could be said that majority of the respondents $21(95.5 \%)$ underlined that their office has a PR tools. Therefore, it could certainly be said that most of the practitioners produce public relation tools such as printed and graphic communication, and broadcast media in the form of news release. However, due to budget constraint all communication tools are not used by the practitioners regularly. There are a number of communication tools that the public relations practitioners use to address the different publics that they have. http://download.nos.org/srsec335new/ch20.pdf

\section{Challenges while practicing PR}

Table 10: Response of the practitioners on having challenges

\begin{tabular}{|c|c|c|c|}
\hline S/N & Alternatives & Frequency & Percent \\
\hline 1 & Yes & 19 & 86.4 \\
\hline 2 & No & 3 & 13.6 \\
\hline \multicolumn{2}{|c|}{ Total } & 22 & 100.0 \\
\hline
\end{tabular}

As could be observed from the table, most of the practitioners 19(86.4) boldly said 'Yes' which indicates that the practitioners are close friends of the challenges. The main challenges stated by the practitioners are:

- Lack of skilled human power(professionals)

- Passive attitude towards the office (belittling) especially from the top leaders

- Absence of adequate capacity building trainings

- Structure of the office (personnel)

- Lack of logistics(electronic) and financial constraint

- Absence of professional leadership

- Infrastructure (to reach village publics)

- reluctance of sector offices

- Inadequate assistance from the region's communication bureau

Therefore, at this juncture it is possible to conclude that this bulky of challenges are threats to the practice of professional public relations and public dissatisfaction on the daily activities which may lead to lack of good governance. Agee (1985) says "public relation practice-at its best affords genuine opportunities for meaningful service to the society."

Table 11: Response of the practitioners on presence of attempts to overcome challenges

\begin{tabular}{|c|c|c|}
\hline Alternatives & Frequency & Percent \\
\hline Yes & 8 & 40 \\
\hline No & 12 & 60 \\
\hline Total & 20 & 100.0 \\
\hline
\end{tabular}




\section{International Journal of Science and Research (IJSR) \\ ISSN (Online): 2319-7064}

Index Copernicus Value (2015): 78.96 | Impact Factor (2015): 6.391

Table 12 table depicts, $12(60 \%)$ of the respondents said 'Yes' whereas $8(40 \%)$ replied 'No'. The respondents even stated that neither of the Wereda nor the zone has been trying to bring a perpetual remedy to exercise their profession effectively and efficiently. Most of the respondents pressed that their 'commitment' has shown them a way to try he best. Therefore, it could safely be concluded that the professional practice of the public relations is somehow questionable. Most of the leaders do not understand what PR is, and some of those who even familiar with the concept are not ready to give full time employment and/or due emphasis.

\section{Conclusion}

Based on the research findings, the researcher has forwarded the following conclusions.

a) Concerning Stakeholders' Perception towards Public Relations

- It was found that both the PR practitioners and employees of sector offices believed that the Public relations office has a key role in the overall activities of the wereda whereas the employees limited the role to publicity which is one part of the Public relations function.

- The finding also depicted that most of the PR practitioners have not perceived the management function of Public Relations.

- As the study showed us the PR office has not involved in creating mutual understanding with the publics of the wereda as it is expected of.

- According the respondents, the PR office was not structured and organized professionally which emanates from belittling its role especially from the top leaders.

- The practitioners remain stages the debate rather than mediate the debate.

b) Regarding the Public Relations office's attempt to reach the public

- The study also identified that the PR office was passive in reaching its publics (internal and external)on regular basis

- Though the PR offices used Public Relation tools to reach the public, the tools are not enough in kind and frequency.

c) Challenges while practicing PR

The study also depicted that

- Lack of skilled human power(professionals),

- Passive attitude towards the office (belittling) especially from the top leaders,

- absence of adequate capacity building trainings, Structure of the office(personnel),

- Lack of logistics(electronic equipments) and financial constraint, absence of professional leadership,

- Lack of infrastructure (to reach village publics),

- reluctance of sector offices, and

- Inadequate assistance from the region's communication bureau was the major challenges while practicing Public Relations in the Weredas of Eastern Zone of Tigray.

According to the respondents (PR practitioners), the efforts made by the Wereda and Zone to overcome the abovementioned challenges were questionable.

\section{Recommendation}

On the basis of the conclusions drawn, the researcher forwards the following recommendations:

- The practitioners should internalize the concept of PR and try to convince the internal publics (sector offices) that it can add something to have healthy relation with the clients.

- The Wereda and other concerned bodies like Tigray Government Communication Affairs office and academic institutions should work jointly to build the capacity of the PR practitioners to strengthen professional practice of public relations.

- The Wereda, especially, should strive to create conducive environment and build the capacity of the Public relations department by allocating adequate budget; by giving adequate training to enrich the potential of the practitioners in the field and recognizing their effort.

- The Zonal administration should try its best to appoint people who are close to the profession so that they can lead the office professionally.

- Up to date PR tools should be used in kind and frequency

- All in all, and if a conducive environment prevails and appropriate measures are taken, better prospects lie ahead for the practice of professional public relations.

\section{References}

[1] Boyce, C., et al. (2006). Conducting In-Depth Interviews: A guide for designing and conducting indepth interviews for evaluation input: pathfinder international

[2] Brian and Deirdre (2009). Putting the Public Back in Public Relations New Jersey Pearson Education, Inc.

[3] Buddenbaum, M. \& Novak B., K. (2001). Applied Communication Research. USA: Iowa State University Press.

[4] Cresswell, J.W.\& Clark, V.P.(2007). Designing and conducting mixed methods of research. London: SAGE Publication. Dornyei (2007:39)

[5] EM Griffin(2012). A first look at communication theory $\left(8^{\text {th }}\right.$ ed $)$ :McGraw-Hill Companies

[6] Cutlip, S. M., Center, A. H., \& Broom, G. T. (2000). Effective public relations (8th ed.).

[7] Englewood Cliffs, NJ: Prentice Hall.

[8] Harrower (2007) Inside Reporting: A practical Guide to the craft of journalism. McGraw-Hill Companies

[9] K. Agee, etal (1985). Introduction to Mass Communications $\left(8^{\text {th }}\right.$ ed) New York Harper \& Row, publishers Inc.

[10] Nolte, L. (1974). Fundamentals of Public Relations. Pergamon Press Inc..

[11] M. Zappala and R. Carden(2004). Public Relations Work text: A Writing and Planning Resource $\left(2^{\text {nd }}\right.$ ed $)$ New Jersey Lawrence Erlbaum Associates, Inc., Publishers

[12] Nigussie Tefera. (2008). Communication For Social Development: An overview and the Ethiopian experience. PMC-Ethiopia.

\section{Volume 6 Issue 1, January 2017




\section{International Journal of Science and Research (IJSR) \\ ISSN (Online): 2319-7064}

Index Copernicus Value (2015): 78.96 | Impact Factor (2015): 6.391

[13] Shri.A.M.Ramachandraiah \& Shri.N.Palaniappan (nd) Trainee's Hand book on Public Relations UNDP / DOPT, Government of India

[14] Vivan J.( 2003). The Media of Mass Communication. Boston: USA Pearson Education, Inc

[15] Wilcox, Dennis L., Ault, Phillip H. and Agee, Warren K., Publication Relations Strategies and Tactics, Harper Collins Publishers Inc., New York ,1992

[16] Problems associated with the practice of public relation https://philipatawura.wordpress.com

[17] Public Relation tools http://download.nos.org/srsec335new/ch20.pdf 